\title{
The effect of endometriosis on sexual function as assessed with the Female Sexual Function Index: systematic review and meta-analysis
}

Faustino R. Pérez-López , Lía Ornat, Gonzalo R. Pérez-Roncero , María T. López-Baena, Manuel Sánchez-Prieto \& Peter Chedraui

To cite this article: Faustino R. Pérez-López , Lía Ornat, Gonzalo R. Pérez-Roncero, María T. López-Baena , Manuel Sánchez-Prieto \& Peter Chedraui (2020): The effect of endometriosis on sexual function as assessed with the Female Sexual Function Index: systematic review and metaanalysis, Gynecological Endocrinology, DOI: 10.1080/09513590.2020.1812570

To link to this article: https://doi.org/10.1080/09513590.2020.1812570

View supplementary material ¿

\section{Published online: 03 Sep 2020.}

Submit your article to this journal $\mathbb{}$

Ш Article views: 2

Q View related articles $\sqsubset$

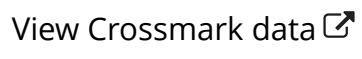




\title{
The effect of endometriosis on sexual function as assessed with the Female Sexual Function Index: systematic review and meta-analysis
}

\author{
Faustino R. Pérez-López ${ }^{\mathrm{a}, \mathrm{b}}$ (D) Lía Ornat ${ }^{\mathrm{b}}$ (D) Gonzalo R. Pérez-Roncero ${ }^{\mathrm{a}}$ (D) María T. López-Baena ${ }^{\mathrm{a}}$ (D), \\ Manuel Sánchez-Prieto ${ }^{c}$ (D) and Peter Chedraui ${ }^{d}$ (D)
}

${ }^{a}$ Instituto de Investigación Sanitaria de Aragón, Zaragoza, Spain; ${ }^{b}$ Department of Obstetrics and Gynecology, University of Zaragoza Faculty of Medicine, Zaragoza, Spain; 'Departament of Obstetrics and Gynecology, Instituto Universitario Dexeus, Barcelona, Spain; ${ }^{d}$ Instituto de Investigación e Innovación en Salud Integral, Facultad de Ciencias Médicas, Universidad Católica de Santiago de Guayaquil, Guayaquil, Ecuador

\begin{abstract}
Aim: To systematically compare sexual function between non-treated women with and without endometriosis.

Methods: A systematic review was performed on PubMed/Medline, Scopus, EMBASE, Web of Science and Cochrane Library databases searching studies that analyzed sexual function (assessed with the 19-item Female Sexual Function Index [FSFI]), and dyspareunia, chronic pelvic pain and dysmenorrhea (assessed with a visual analogue scale [VAS]) in women with and with endometriosis.

Results: In 4 studies, non-treated women with endometriosis presented a higher risk of female sexual dysfunction (mean total FSFI score $\leq 26.55$; OR $=2.38 ; 95 \%$ confidence interval $[\mathrm{Cl}]=1.12,5.04$ ). Although mean total FSFI scores were not significantly different between women with and without endometriosis (mean difference $[\mathrm{MD}]=-2.15 ; 95 \% \mathrm{Cl}-4.96,0.67$ ); all FSFI domain scores were significantly lower in women with endometriosis ( $n=4$ studies): desire (MD $=-0.43 ; 95 \% \mathrm{Cl}-0.57,-0.19$ ); arousal $(\mathrm{MD}=-0.66 ; 95 \% \mathrm{Cl}-1.15,-0.17)$; lubrication $(\mathrm{MD}=-0.41 ; 95 \% \mathrm{Cl}-0.79,-0.02)$; orgasm (MD = $-0.40 ; 95 \% \mathrm{Cl}-0.73,-0.06)$; satisfaction ( $\mathrm{MD}=-0.45 ; 95 \% \mathrm{Cl}-0.72,-0.18)$; and pain $(\mathrm{MD}=-1.03$; $95 \% \mathrm{Cl}-1.34,-0.72)$. Women with endometriosis displayed differences (more severity) in terms of VAS scores (2 studies) for dyspareunia (MD $=1.88 ; 95 \% \mathrm{Cl} 0.38,3.37)$ and chronic pelvic pain $(\mathrm{MD}=2.92$; $95 \% \mathrm{Cl} 1.26,4.58)$; but not for dysmenorrhea.

Conclusion: Non-treated women with endometriosis displayed altered sexual function as evidenced by lower scores in all FSFI domains, and severity of dyspareunia and chronic pelvic pain.
\end{abstract}

ARTICLE HISTORY

Received 23 June 2020

Revised 17 August 2020

Accepted 17 August 2020

Published online 3 Septem-

ber 2020

\section{KEYWORDS}

Chronic Pelvic Pain;

Dyspareunia; Endometriosis; Female Sexual Dysfunction;

Female Sexual Function Index; Visual Analogue

Scale

\section{Introduction}

Female sexual dysfunction, particularly painful sex, is a common complaint in adult women of all ages. During reproductive years, endometriosis is a highly prevalent gynecological disease. Persistent sexual pain related to endometriosis has been associated to biological, psychological, sexual and interpersonal factors [1]. Clinical symptoms of endometriosis include dysmenorrhea, chronic pelvic pain, dyspareunia, lumbar pain, dyschezia, dysuria and infertility. The prevalence of sexual dysfunction in women with endometriosis is almost double as compared to those with other gynecological disorders [2]. Dyspareunia and chronic pelvic pain negatively impact several domains of sexual function, especially in women with deep infiltrating endometriosis (DIE) and rectovaginal or bowel endometriosis as compared to other forms of endometriosis or healthy women [3-5]. There are also psychological consequences, including mood swings, depressive and anxious symptoms that, at the same time, may increase pelvic discomfort [6-8]. The objective of this systematic review and meta-analysis is to compare sexual function between non-treated women with and without endometriosis.

\section{Methods}

\section{Protocol, search strategy, eligibility criteria and study selection}

The systematic review and meta-analysis was carried out following the principles of the PRISMA guidelines [9]. Formal institutional review board approval was not required, as this analysis consisted of the pooling of published studies.

A systematic literature search was conducted in PubMedMedline, Scopus, EMBASE, and Web of Science databases from inception through March 9 2020, and without language restrictions. We searched for free terms 'endometriosis' $O R$ 'endometrioma' OR 'rectovaginal endometriosis' AND 'sexual functioning' $O R$ 'sexual dysfunction' $O R$ 'sexuality' $O R$ 'dyspareunia' OR 'sexual life'. The Pubmed search strategy is available in Appendix A (Supplementary Table A1). An iterative process was used to ensure that all relevant articles were obtained. A further manual search of bibliographic references was also carried out in selected studies and in existing reviews to identify potential studies that were not captured by the electronic database searches.

CONTACT: Faustino R. Pérez-López faustino.perez@unizar.es Department of Obstetrics and Gynecology, University of Zaragoza Faculty of Medicine, Domingo Miral s/n, Zaragoza, 50009, Spain

(4) Supplemental data for this article is available online at https://doi.org/10.1080/09513590.2020.1812570. 
Eligible for inclusion were relevant cohort and case-control studies that: (i) assessed women of reproductive age with clinical endometriosis and those without endometriosis who were not receiving any hormonal treatment; (ii) evaluated sexual function/ dysfunction as assessed with a validated sexual function/dysfunction questionnaire; (iii) were in any language irrespective of age, race, and date of publication; and (iv) were addressing the same population if they reported complementary information to the main paper. Articles were excluded if they were narrative reviews, abstracts and conference proceedings, or non-human studies. All disagreements regarding inclusion/exclusion were discussed and solved by consensus with all authors. Meta-analyses were predefined/planned for each validated sexuality questionnaire if reported in at least two different populations.

\section{Data extraction and risk of bias assessment}

A Microsoft Excel sheet was designed for data input. Two researchers extracted publication details, eligibility and exclusion criteria, as well as information about the study population and design, period of study, sample size and clinical characteristics of the studied population. Discrepancies and controversies of extracted data were discussed in order to reach a consensus. Due to the fact that some results were reported as medians and their $25 \%$ and $75 \%$ confidence intervals, appropriate calculations were performed to obtain mean and standard deviations that served for the meta-analysis [10].

The methodological quality of the selected studies was independently assessed by two authors using the Newcastle-Otawa Scale for case-controls studies [11]. This scale consists of three broad perspectives including the selection of the study group, the comparability of the groups, and the ascertainment of the primary outcome. The maximum score can be 9 stars. Studies with seven star-items or more are categorized as high quality and those with six star-items or less as low quality.

\section{Data synthesis and analysis}

Forest plots were planned for outcomes reported in at least two studies using any validated test to assess female sexual function, using DerSimonian and Laird random-effects models and the inverse variance method [12]. Associations among dichotomous outcomes are reported as odds ratio (OR); and for continuous outcomes mean differences (MDs), both with their corresponding 95\% confidence interval (CI). We evaluated statistical heterogeneity using the Cochrane chi square $\left(\mathrm{X}^{2}\right)$, the $I^{2}$ statistic, and the between-study variance using the tau square $\left(\tau^{2}\right)[13,14]$. $I^{2}$ values of $30-75 \%$ indicate a moderate level of heterogeneity. A $p<.1$ for the chi-square defined the presence of heterogeneity; and a $\tau^{2}>1$ defines the presence of substantial statistical heterogeneity. We planned to estimate the publication bias if there are at least 10 studies reporting the same outcome [15].

The Review Manager program (RevMan, version 5.3, Oxford, UK; The Cochrane Collaboration) was used for statistical analyses.

\section{Results}

\section{Selection and characteristics of the studies}

A total of 366 records were identified through systematic database searches and 3 through other sources (Figure 1). After the removal of duplicates, 314 items were screened by title, leaving
74 for review of abstract content. Eligibility was assessed in 23 full text articles, leaving a total of eleven. Seven of these papers were excluded, four that did not have a control group and three that reported in each one data of sexual function assessed by a different tool. There was one study using the Female Health Outcomes in Women questionnaires [2], one study with the McCoy Female Sexuality Questionnaire [16], one study with the Female Sexual Quotient [5], and four studies using the Female Sexual Function Index (FSFI) [17]. Therefore, a total of 4 studies reporting results with the FSFI were included in this meta-analysis (Figure 1) [18-21]. The general characteristics and main relevant clinical and socio-demographic findings of patients included in the 4 studies are presented in Table 1.

The FSFI is a 19-item self-reported instrument used to measure overall sexual function in the past 4 weeks in women who are sexually active and have a partner. The tool is composed of six domains of sexual function each providing a score. The sum of all domain scores yields a total FSFI score. These domains are: desire ( 2 items, questions $1 \& 2$ ), arousal ( 4 items, questions $3 \& 4$ and $5 \& 6$ ), lubrication (4 items, questions $7 \& 8$ and $9 \& 10$ ), orgasm (3 items, questions $11 \& 12 \& 13$ ), satisfaction (3 items, questions $14 \& 15 \& 16$ ), and pain ( 3 items, questions $17 \& 18 \& 19$ ) [17]. A total FSFI score of $\leq 26.55$ was used to define women at higher risk of sexual dysfunction [22].

\section{Meta-analysis of sexual function and dyspareunia}

There were no significant mean differences (MD) in terms of age $(\mathrm{MD}=1.69$ years, $95 \% \mathrm{CI}-0.14,3.53$; Figure $2(\mathrm{~A}))$ and total 19-item FSFI scores $(\mathrm{MD}=-2.15,95 \% \mathrm{CI}-4.96,0.67$; Figure 2(B)) when comparing women with and without endometriosis [18-21]. Despite finding no differences in mean total FSFI scores, women with endometriosis displayed a higher risk of sexual dysfunction (defined as a total FSFI score $\leq 26.55$ ) [22] $(\mathrm{OR}=2.38 ; 95 \%$ CI 1.12, 5.04, $n=3$ studies; Figure $2(\mathrm{C}))[18,19$, 21]. Women with endometriosis displayed lower scores in each of the FSFI domains: desire ( $\mathrm{MD}=-0.43$; 95\% CI $-0.67,-0.19$, Figure 3(A)); arousal $(\mathrm{MD}=-0.66 ; 95 \% \mathrm{CI}-1.15,-0.17$; Figure $3(\mathrm{~B})$ ); lubrication ( $\mathrm{MD}=-0.41 ; 95 \% \mathrm{CI}-0.79,-0.02$; Figure $3(\mathrm{C})$ ); orgasm $(\mathrm{MD}=-0.40 ; 95 \% \mathrm{CI}-0.73,-0.06$; Figure $3(\mathrm{D}))$; satisfaction $(\mathrm{MD}=-0.45 ; 95 \% \mathrm{CI}-0.72,-0.18$; Figure $3(\mathrm{E})$ ), and pain $(\mathrm{MD}=-1.03$; 95\% CI $-1.34,-0.72$; Figure $3(\mathrm{~F}))$ [18-21].

In two studies, visual analogue scale (VAS) pain scores for dyspareunia were significantly higher in women with endometriosis $(\mathrm{MD}=1.88 ; 95 \%$ CI $0.38,3.37$; Figure 4(A) $)[18,19]$. Dyspareunia would had been worse if one takes into account that 7 additional women with endometriosis and one without endometriosis in the De Graaf et al. study were unable to maintain/have sexual intercourse [18]. Chronic pelvic pain was also assessed with a VAS, also showing significantly more pain severity in women with endometriosis as compared to controls (MD $=2.92 ; 95 \%$ CI 1.26, 4.58; Figure 4(B)) [18,19]. Finally, there were no significant differences in terms of dysmenorrhea intensity between women with and without endometriosis as assessed with the VAS (MD = 1.80: 95\% CI -2.63, 6.23; Figure $4(\mathrm{C}))[18,19]$.

\section{Risk of bias}

Appendix A, Supplementary Table A2 displays the assessment of risk of bias by means of the Newcastle-Otawa Scale [11], showing a low risk of bias (score $\geq 7$ ). 


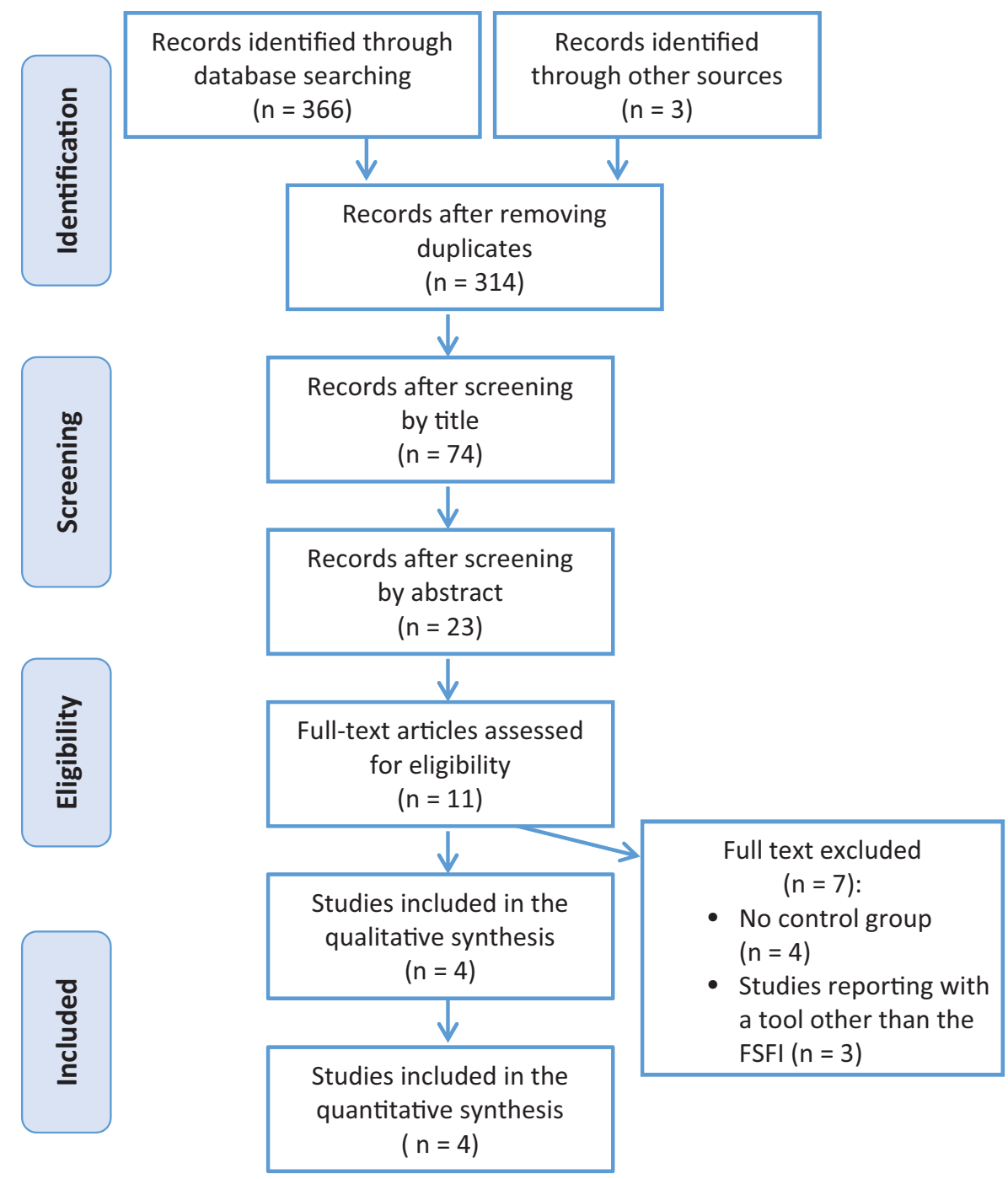

Figure 1. Flowchart of study selection.

\section{Publication bias}

Since there were only 4 studies, we were unable to calculate publication bias with the funnel plot and the Egger's test [15].

\section{Discussion}

The present meta-analysis found that un-treated women with endometriosis in their early fourth decade of life have an increased risk of sexual dysfunction, dyspareunia and chronic pelvic pain in comparison to those without endometriosis. Despite this, no significant differences were found in relation to the severity of dysmenorrhea. Endometriosis is a chronic gynecological disease that causes a negative impact on physical, psychological and sexual aspects of life. Regarding sexuality, the impact of the disease has been studied in different clinical conditions, treatment scenarios, associated to infertility, and general health and quality of life. Sexual function is severely compromised in women who smoke, have dyspareunia, severe chronic pelvic pain, bladder syndrome, and an increased body mass index or a family history of chronic pain $[23,24]$.

Systematic reviews have analyzed sexual function or dysfunction among women with endometriosis who had been receiving various treatments, indicating that more than half of these women suffer some type of sexual dysfunction [25,26]. Although surgical and pharmacological treatments may improve sexual function among women with endometriosis, in some cases discomfort during intercourse and sexual dysfunction may persist [27]. Despite this, to date we are not aware of any meta-analysis that compares female sexual function and different forms of genital pain between untreated women with and without endometriosis.

Among the few available studies, we found 4 reporting the assessment of sexual function with the 19-item FSFI. This questionnaire is a useful tool for the evaluation of female sexual function, and its total score allows us to objectively screen women who are at a higher risk of sexual dysfunction [20, 28]. In our study, although mean total FSFI scores did not differ among cases and controls; significant lower scores for each of the domains of the FSFI were found in women with endometriosis, suggesting that endometriosis has impaired their sexuality. Alterations of sexual function in women with endometriosis are not only related to the disease per se and its stage, yet also to other factors such as anxiety, depression, sleep problems, excessive body weight and less physical activity [29].

Women with endometriosis may have severe chronic pelvic pain, dysmenorrhea, dischezia, and urinary symptoms. We found significant higher mean dyspareunia VAS scores in women with 


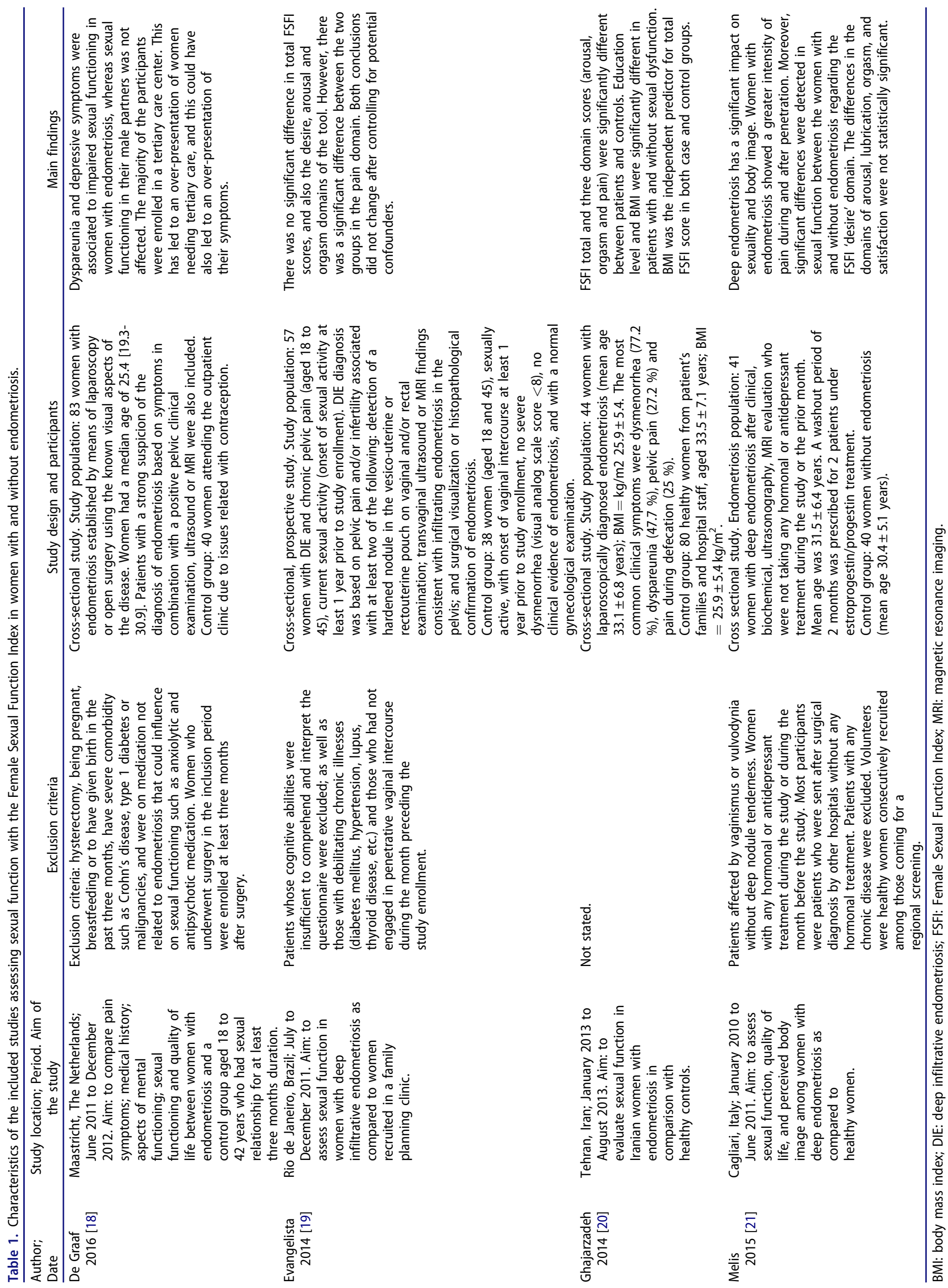


(A)

\begin{tabular}{|c|c|c|c|c|c|c|c|c|c|c|c|c|}
\hline \multirow[b]{2}{*}{ Study or Subgroup } & \multicolumn{3}{|c|}{ Endometriosis } & \multicolumn{3}{|c|}{ Control group } & \multirow[b]{2}{*}{ Weight } & \multirow{2}{*}{$\begin{array}{l}\text { Mean Difference } \\
\text { IV, Random, } 95 \% \mathrm{Cl}\end{array}$} & \multirow{2}{*}{\multicolumn{4}{|c|}{$\begin{array}{l}\text { Mean Difference } \\
\text { IV, Random, } 95 \% \mathrm{Cl}\end{array}$}} \\
\hline & Mean & SD & Total & Mean & SD & Total & & & & & & \\
\hline Evangelista A, 2014 & 35.4 & 5.2 & 57 & 31 & 7.8 & 38 & $22.3 \%$ & $4.40[1.58,7.22]$ & & & & {[} \\
\hline Ghajarzadeh M, 2014 & 33.1 & 6.8 & 44 & 33.5 & 7.1 & 80 & $24.8 \%$ & $-0.40[-2.94,2.14]$ & & & & \\
\hline Melis I, 2015 & 31.49 & 6.44 & 41 & 30.37 & 5.1 & 40 & $25.0 \%$ & $1.12[-1.41,3.65]$ & & & & \\
\hline De Graaf AA, 2016 & 34.3 & 4.5 & 83 & 32.4 & 6.5 & 40 & $27.8 \%$ & $1.90[-0.33,4.13]$ & & & & \\
\hline Total $(95 \% \mathrm{Cl})$ & & & 225 & & & 198 & $100.0 \%$ & $1.69[-0.14,3.53]$ & & & & \\
\hline \multicolumn{7}{|c|}{$\begin{array}{l}\text { Heterogeneity: } \operatorname{Tau}^{2}=1.85 ; \mathrm{Chi}^{2}=6.36, \mathrm{df}=3(\mathrm{P}=0.10) ; \mathrm{I}^{2}=53 \% \\
\text { Test for overall effect: } Z=1.81(P=0.07)\end{array}$} & & & $\frac{1}{-10}$ & רdometriosis & Control gr & 5 \\
\hline
\end{tabular}

(B)

Total FSFI score

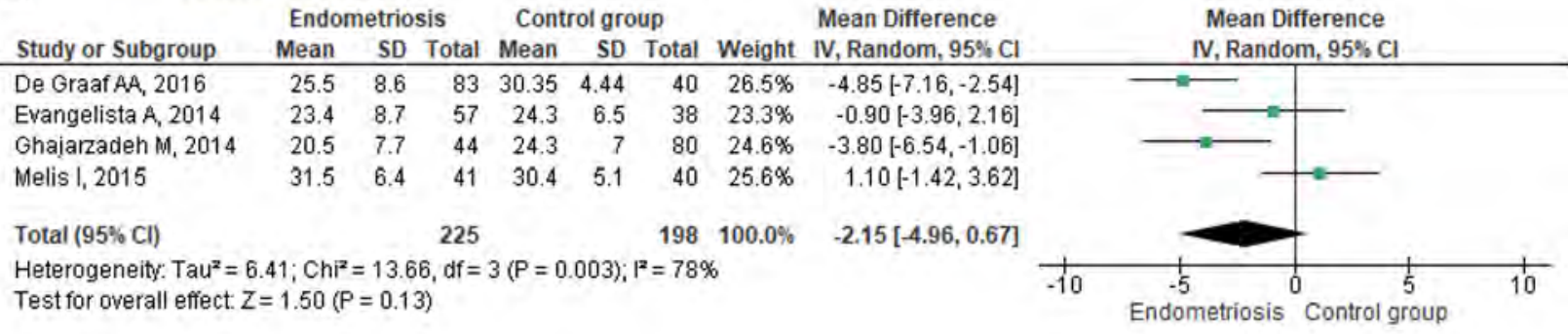

(C)

Women with FSFI $\leq 26.55$

\begin{tabular}{|c|c|c|c|c|c|c|c|c|c|}
\hline \multirow[b]{2}{*}{ Study or Subgroup } & \multicolumn{2}{|c|}{ Endometriosis } & \multicolumn{2}{|c|}{ Control group } & \multicolumn{2}{|r|}{ Odds Ratio } & & \multirow{2}{*}{\multicolumn{2}{|c|}{$\begin{array}{c}\text { Odds Ratio } \\
\mathrm{M}-\mathrm{H}, \text { Random, } 95 \% \mathrm{Cl}\end{array}$}} \\
\hline & Events & Total & Events & Total & Weight & M-H, Random, $95 \% \mathrm{Cl}$ & & & \\
\hline De Graaf AA, 2016 & 43 & 83 & 7 & 41 & $32.3 \%$ & $5.22[2.08,13.11]$ & & & \\
\hline Evangelista A, 2014 & 40 & 57 & 23 & 38 & $34.3 \%$ & $1.53[0.65,3.64]$ & & & \\
\hline Melis I, 2015 & 21 & 41 & 15 & 40 & $33.5 \%$ & $1.75[0.72,4.24]$ & & & \\
\hline Total $(95 \% \mathrm{Cl})$ & & 181 & & 119 & $100.0 \%$ & $2.38[1.12,5.04]$ & & & \\
\hline Total events & 104 & & 45 & & & & & & \\
\hline $\begin{array}{l}\text { Heterogeneity. Tau² = } \\
\text { Test for overall effect: }\end{array}$ & $\begin{array}{l}0.23 ; \mathrm{Chi}^{2} \\
Z=2.26(\mathrm{P}\end{array}$ & $\begin{array}{l}4.27, d \\
0.02)\end{array}$ & $f=2(P=$ & 12); $\left.\right|^{2}$ & $=53 \%$ & & 0.05 & $\begin{array}{l}0.2 \\
\text { Control group }\end{array}$ & Endome \\
\hline
\end{tabular}

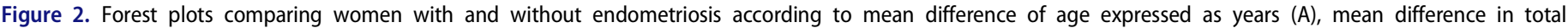
Female Sexual Function Index score (B), and risk of female sexual dysfunction (odds ratio) according to the FSFI cutoff of $\leq 26.55$ (C).

endometriosis in comparison to the controls. It is important to mention that 7 women with endometriosis and one without in the De Graaf et at.[18] study were unable to maintain sexual intercourse due to their history of extreme dyspareunia; hence it can be presumed that this outcome would be even worse (higher VAS score) if more studies and/or cases were available. Previous publications have reported that women with endometriosis who receive endocrine treatments achieve significant relief of their dyspareunia while increasing their total FSFI scores (better sexual function); although in some cases sexual function is not completely restored $[30,31]$.

Chronic pelvic pain is a complex problem observed in women during their reproductive years. In this sense, endometriosis is a common cause, but symptoms are not constant and may vary among populations and throughout time, in fact decreasing or disappearing after menopause. In the present meta-analysis, we also found information regarding chronic pelvic pain, assessed with the VAS, in 2 of the 4 selected FSFI studies. Analysis found significant differences in terms of more intense chronic pelvic pain in women with endometriosis as compared to those without the disease. It seems that endometriosis alters peritoneal homeostasis and induces the production of pro-inflammatory and angiogenic cytokines [32]. Pelvic pain due to DIE may also be related to compression or infiltration of endometriotic implants in the sub-peritoneal space [33]. Endometriotic lesions are present in some 30 to $40 \%$ of women subject to laparoscopy due to chronic pelvic pain [34]. However, a $25 \%$ of cases can be asymptomatic which may be related to different factors with no clear or consistent patterns found [35]. Chronic pelvic pain may also be related to psychological dysfunction, anxiety and depression, decreased levels of self-compassion and emotional regulation, a history of sexual abuse, previous surgery, and urinary or digestive alterations [36-38].

The present meta-analysis found no significant differences in terms of VAS scores for dysmenorrhea. Dysmenorrhea may be associated to chronic pelvic and also non-pelvic causes. A recent meta-analysis pointed out that women with dysmenorrhea have a higher risk of chronic pelvic pain as compared to those without dysmenorrhea [39]. On the other hand, dyspareunia and dysmenorrhea are less intense in women who only have ovarian endometriosis in comparison to other locations [40]. In fact, as assessed with different tools, the extension and pain due to endometriosis are not consistently related.

\section{Limitations}

The principal limitation of our meta-analysis is the availability of few studies with only four publications directly comparing sexual function assessed with the FSFI among un-treated women with and without endometriosis. Unfortunately, three studies had to be excluded due to the fact that each one used a different tool 
(A)

\section{FSFI: Desire}

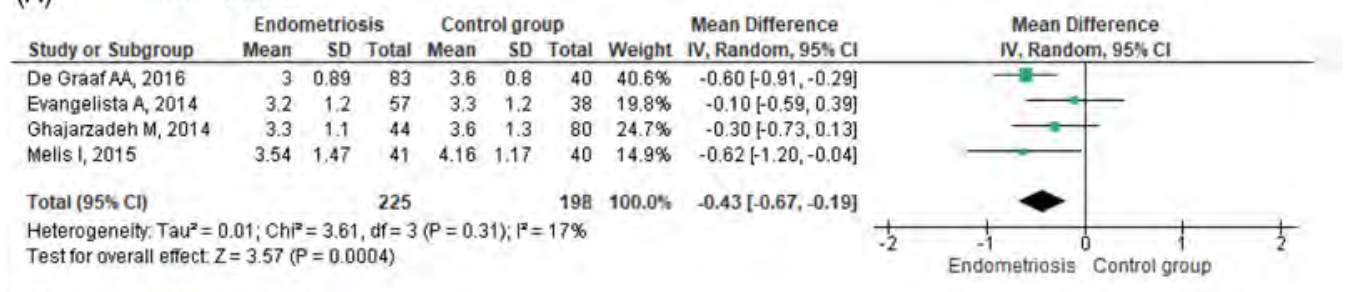

(B)

\section{FSFI: Arousal}

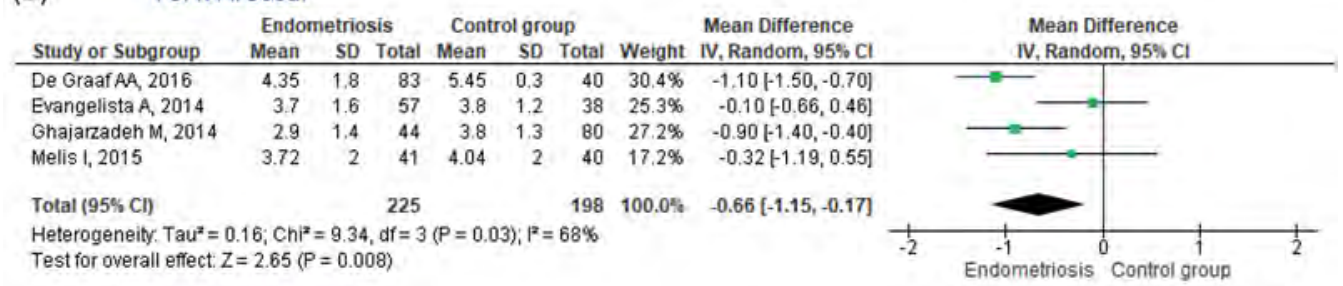

(C)

\section{FSFI: Lubrication}

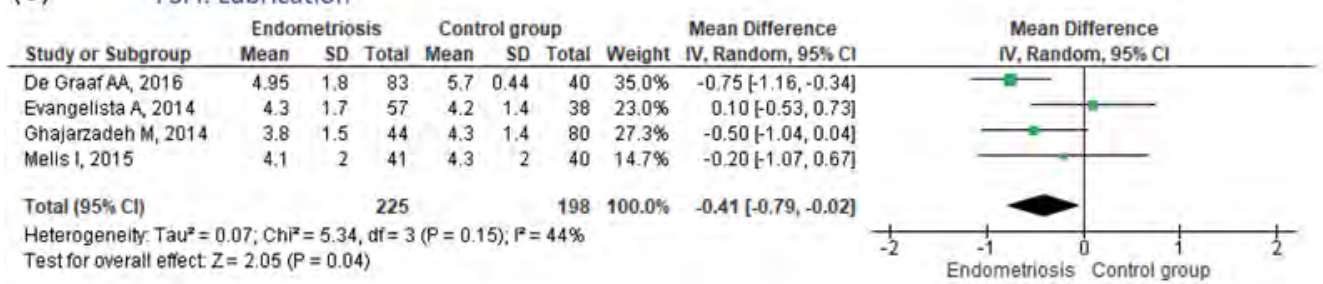

(D)

\section{FSFI: Orgasm}

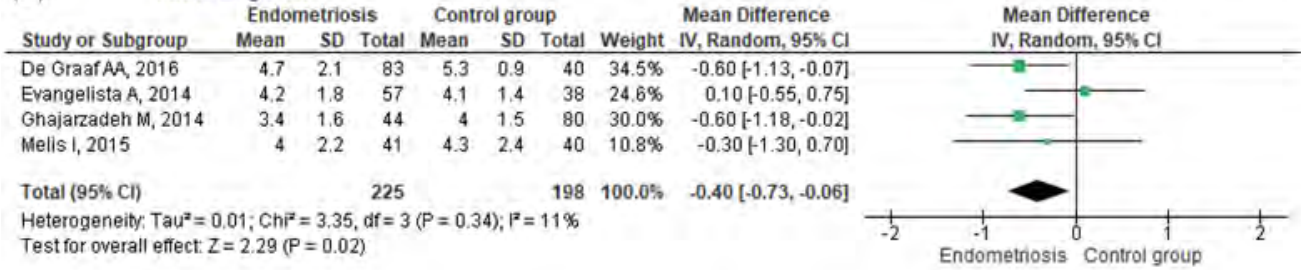

(E)

FSFI: Satisfaction

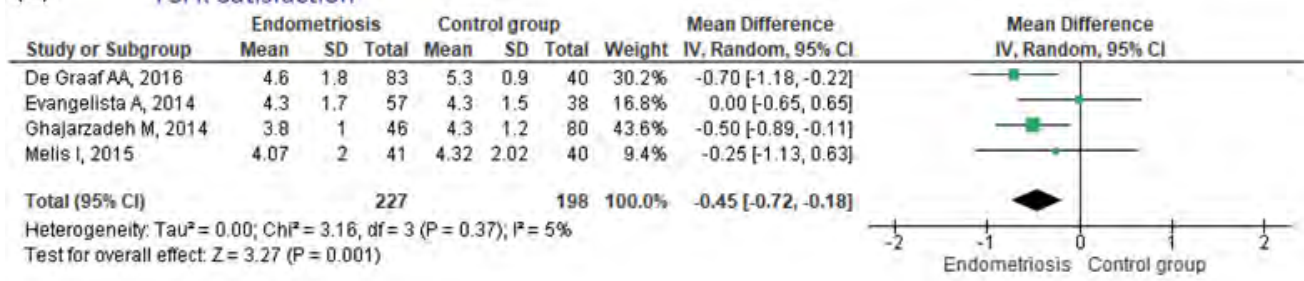

(F)

\section{FSFI: Pain}

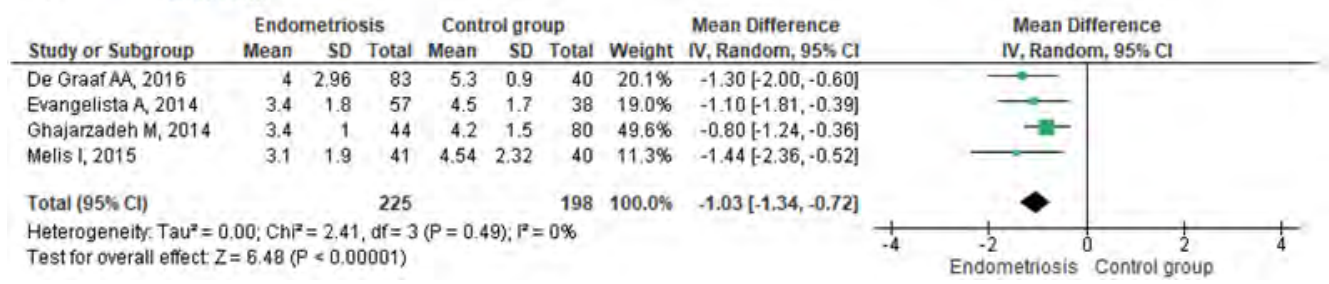

Figure 3. Forest plots comparing (mean difference) women with and without endometriosis according to scores obtained for each FSFI domain: desire (A), arousal $(B)$, lubrication $(C)$, orgasm $(D)$, satisfaction $(E)$, and pain $(F)$.

$[2,5,16]$. These other tools may provide complementary information not found with the FSFI. Sexual life and expectations may change with age and the presence of endometriosis [41]. Women of our meta-analysis (with and without endometriosis) were in their early thirties; hence one should bear in mind that other age groups may have different sexual function characteristics.
Another limitation of our meta-analysis is that controls were women without endometriosis who attended gynecological consultations for routine checkup, and although having a similar age and being free of symptoms, they were not subjected to any diagnostic laparoscopic procedure specific for women with endometriosis. However this approach would have been unethical. 


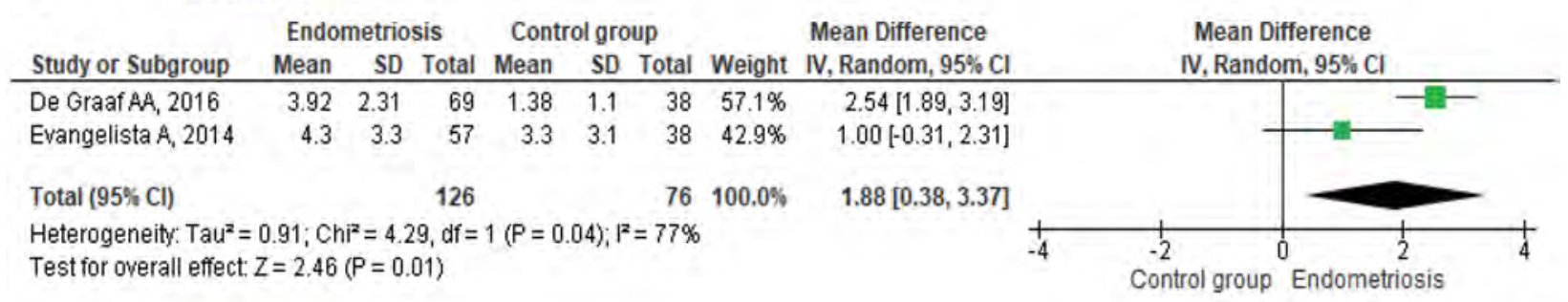

(B) Chronic pelvic pain

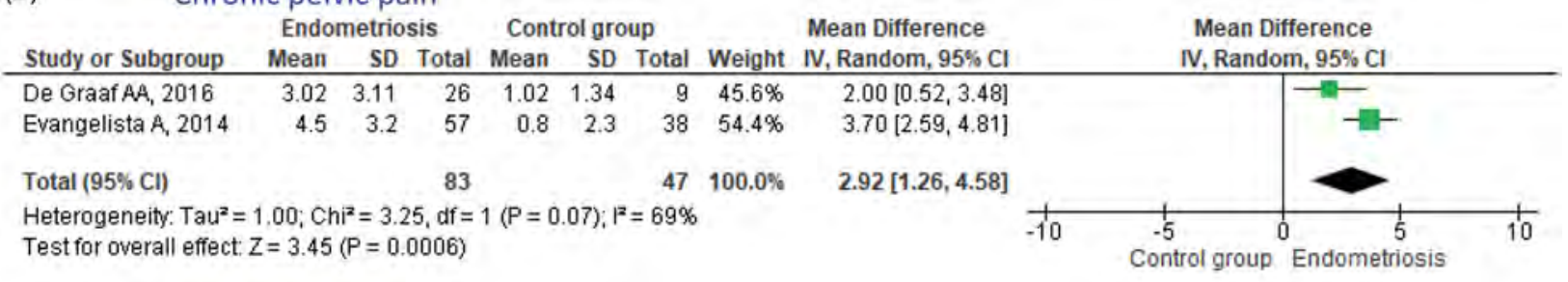

\section{Dysmenorrhea}

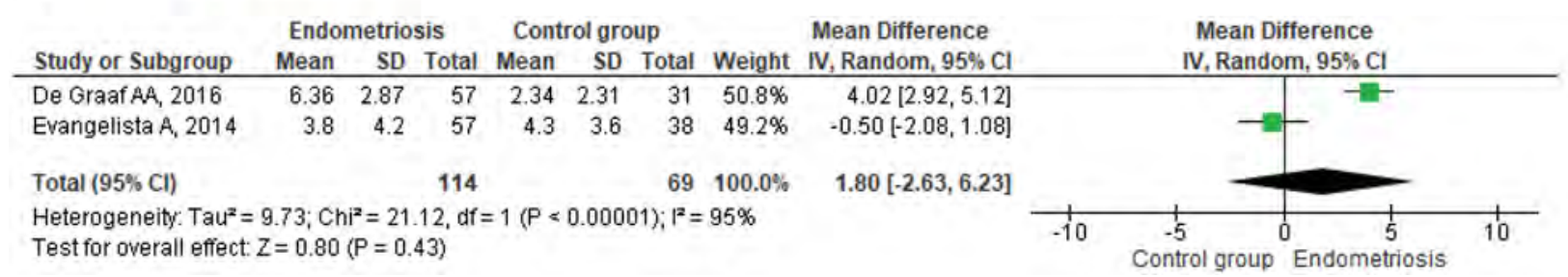

Figure 4. Forest plots comparing (mean difference) women with and without endometriosis according to VAS scores obtained for: dyspareunia (A), chronic pelvic pain (B), and dysmenorrhea (C).

Our meta-analysis of dyspareunia showed a significant trend for higher severity scores in women with endometriosis as compared to controls. Studies with larger samples have reported a higher prevalence of dyspareunia in women with endometriosis, although this symptom may also be unrelated to the disease $[42,43]$. Several studies have reported that dyspareunia is highly frequent in women with DIE who also present voiding alterations and psychological distress [25, 44,45]. Despite this, other causes of painful sex in women with endometriosis include depression or psychological stress [46]. Future studies should combine the assessment of dyspareunia along with the use of tools that evaluate depressive/anxiety symptoms, and emotional and sexual function.

\section{Strengths}

The first strength of our study is that it meta-analyzed data using the FSFI. This tool has been widely used to assess female sexual function, and its components, in quite different circumstances, diseases and populations throughout nearly two decades $[47,48]$. Secondly, we analyzed cases and controls that had a similar age, allowing equal comparisons in terms of social and sexual behavior. Despite these strengths, there is a need for studies performed in younger women in order to: i) assess the negative impact that the disease has over sexuality; and ii) once identified those with potential sexual dysfunction, evaluate overtime the impact of the disease or interventions.

\section{Conclusion}

Endometriosis is not a homogeneous disease in its anatomical characteristics and clinical symptoms. The meta-analyzed information could not identify these involved factors and also could not speculate about the types and extension of endometriosis due to the small number of included studies. In this sense, one should mention that higher rates of dyspareunia and chronic pain in women with endometriosis do not predict their sexual distress; with metacognitive beliefs having more influence on sexual distress than pain per se [49]. Despite the existence of previous systematic reviews, this is the first meta-analysis that objectively assesses female sexual dysfunction (and different forms of pelvic pain) in un-treated women with endometriosis using the FSFI that evaluates standardized components of sexuality.

\section{Acknowledgements}

The authors thank Prof. Stefano Angione, from the University of Cagliari (Italy), for providing complementary information about the paper by Melis et al. [21], included in the meta-analysis. The authors also thank Ms. M. Salas Valero for her assistance with the study.

\section{Disclosure statement}

The authors report no conflicts of interest and are alone responsible for the content and the writing of the article. 


\section{ORCID}

Faustino R. Pérez-López (iD http://orcid.org/0000-0002-2801-416X Lía Ornat (iD http://orcid.org/0000-0001-9056-2143

Gonzalo R. Pérez-Roncero (iD http://orcid.org/0000-0001-8137-4837

María T. López-Baena (D) http://orcid.org/0000-0002-9890-8003

Manuel Sánchez-Prieto ID http://orcid.org/0000-0001-7366-0446

Peter Chedraui (ID http://orcid.org/0000-0002-1556-3979

\section{References}

[1] Aerts L, Grangier L, Dallenbach P, et al. Understanding sexual pain in endometriosis. Minerva Ginecol. 2019;71(3):224-234.

[2] Di Donato N, Montanari G, Benfenati A, et al. Sexual function in women undergoing surgery for deep infiltrating endometriosis: a comparison with healthy women. J Fam Plann Reprod Health Care. 2015;41(4):278-283.

[3] Vercellini P, Trespidi L, De Giorgi O, et al. Endometriosis and pelvic pain: relation to disease stage and localization. Fertil Steril. 1996; 65(2):299-304.

[4] Montanari G, Di Donato N, Benfenati A, et al. Women with deep infiltrating endometriosis: sexual satisfaction, desire, orgasm, and pelvic problem interference with sex. J Sex Med. 2013;10(6):1559-1566.

[5] Fairbanks F, Abdo CH, Baracat EC, et al. Endometriosis doubles the risk of sexual dysfunction: a cross-sectional study in a large amount of patients. Gynecol Endocrinol. 2017;33(7):544-547.

[6] Missmer SA, Cramer DW. The epidemiology of endometriosis. Obstet Gynecol Clin North Am. 2003;30(1):1-19.

[7] Sepulcri RP, Amaral VF. Depressive symptoms, anxiety, and quality of life in women with pelvic endometriosis. Eur J Obstet Gynecol Reprod Biol. 2009;142(1):53-56.

[8] Brasil DL, Montagna E, Trevisan CM, et al. Psychological stress levels in women with endometriosis: systematic review and meta-analysis of observational studies. Minerva Med. 2020;111(1):90-102.

[9] Moher D, Liberati A, Tetzlaff J, PRISMA Group, et al. Preferred reporting items for systematic reviews and meta-analyses: the PRISMA statement. Int J Surg. 2010;8(5):336-341.

[10] Abraira V. Standard deviation and standard error of the mean. Semergen. 2002;28(11):621-623.

[11] Wells GA, Shea B, O'Connell D, et al. The Newcastle-Ottawa Scale (NOS) for assessing the quality of nonrandomised studies in metaanalyses. [cited 2019 Oct 18]. Available from: http://www.ohri.ca/programs/clinical_epidemiology/oxford.asp.

[12] DerSimonian R, Laird N. Meta-analysis in clinical trials. Control Clin Trials. 1986;7(3):177-188

[13] Higgins JP, Thompson SG, Deeks JJ, et al. Measuring inconsistency in meta-analyses. BMJ. 2003;327(7414):557-560

[14] Higgins JP. Commentary: heterogeneity in meta-analysis should be expected and appropriately quantified. Int J Epidemiol. 2008;37(5): $1158-1160$.

[15] Egger $M$, Smith GD, Schneider $M$, et al. Bias in meta-analysis detected by a simple, graphical test. BMJ. 1997;315(7109):629-634

[16] Giuliani M, Cosmi V, Pierleoni L, et al. Quality of life and sexual satisfaction in women suffering from endometriosis: an Italian preliminary study. Revue Européenne de Sexologie et de. Santé Sexuelle. 2016 25(1):e12-e19.

[17] Rosen R, Brown C, Heiman J, et al. The Female Sexual Function Index (FSFI): a multidimensional self-report instrument for the assessment of female sexual function. J Sex Marital Ther. 2000;26: 191-208.

[18] De Graaff AA, Van Lankveld J, Smits LJ, et al. Dyspareunia and depressive symptoms are associated with impaired sexual functioning in women with endometriosis, whereas sexual functioning in their male partners is not affected. Hum Reprod. 2016;31(11):2577-2586.

[19] Evangelista A, Dantas T, Zendron C, et al. Sexual function in patients with deep infiltrating endometriosis. J Sex Med. 2014;11(1):140-145.

[20] Ghajarzadeh M, Tanha FD, Akrami M, et al. Do Iranian women with endometriosis suffer from sexual dysfunction? Sex Disabil. 2014;32(2): 189-195.

[21] Melis I, Litta P, Nappi L, et al. Sexual function in women with deep endometriosis: Correlation with quality of life, intensity of pain depression, anxiety, and body image. Intern J Sexual Health. 2015; 27(2):175-185.
[22] Wiegel M, Meston C, Rosen R. The Female Sexual Function Index (FSFI): cross-validation and development of clinical cutoff scores. J Sex Marital Ther. 2005;31(1):1-20.

[23] Yosef A, Allaire C, Williams C, et al. Multifactorial contributors to the severity of chronic pelvic pain in women. Am J Obstet Gynecol. 2016;215(6):760.e1-760.e14.

[24] Orr NL, Noga H, Williams C, et al. Deep dyspareunia in endometriosis: role of the bladder and pelvic floor. J Sex Med. 2018;15(8):1158-1166.

[25] Fritzer N, Haas D, Oppelt P, et al. More than just bad sex: sexual dysfunction and distress in patients with endometriosis. Eur J Obstet Gynecol Reprod Biol. 2013;169(2):392-396.

[26] Barbara G, Facchin F, Buggio L, et al. What is known and unknown about the association between endometriosis and sexual functioning: a systematic review of the literature. Reprod Sci. 2017;24(12):1566-1576.

[27] Barbara G, Facchin F, Meschia M, et al. When love hurts. A systematic review on the effects of surgical and pharmacological treatments for endometriosis on female sexual functioning. Acta Obstet Gynecol Scand. 2017;96(6):668-687.

[28] Chedraui P, Pérez-López FR. Assessing sexual problems in women at midlife using the short version of the female sexual function index. Maturitas. 2015;82(3):299-303.

[29] Youseflu S, Jahanian Sadatmahalleh S, Bahri Khomami M, et al. Influential factors on sexual function in infertile women with endometriosis: a path analysis. BMC Womens Health. 2020;20(1):92.

[30] Grandi G, Xholli A, Napolitano A, et al. Pelvic pain and quality of life of women with endometriosis during quadriphasic estradiol valerate/dienogest oral contraceptive: a patient-preference prospective $24-$ week pilot study. Reprod Sci. 2015;22(5):626-632.

[31] Leonardo-Pinto JP, Laguna Benetti-Pinto C, Angerame Yela D. When solving dyspareunia is not enough to restore sexual function in women with deep infiltrating endometriosis treated with dienogest. J Sex Marital Ther. 2019;45(1):44-49.

[32] Triolo O, Laganà AS, Sturlese E. Chronic pelvic pain in endometriosis: an overview. J Clin Med Res. 2013;5(3):153-163.

[33] Fauconnier A, Chapron C. Endometriosis and pelvic pain: epidemiological evidence of the relationship and implications. Hum Reprod Update. 2005;11(6):595-606.

[34] Neis KJ, Neis F. Chronic pelvic pain: cause, diagnosis and therapy from a gynaecologist's and an endoscopist's point of view. Gynecol Endocrinol. 2009;25(11):757-761.

[35] Schliep KC, Mumford SL, Peterson CM, et al. Pain typology and incident endometriosis. Hum Reprod. 2015;30(10):2427-2438.

[36] Bryant C, Cockburn R, Plante AF, et al. The psychological profile of women presenting to a multidisciplinary clinic for chronic pelvic pain: high levels of psychological dysfunction and implications for practice. J Pain Res. 2016;9:1049-1056.

[37] Sewell M, Churilov L, Mooney S, et al. Chronic pelvic pain - pain catastrophizing, pelvic pain and quality of life. Scand J Pain. 2018; 18(3):441-448.

[38] Vasconcelos P, Oliveira C, Nobre P. Self-compassion, emotion regulation, and female sexual pain: a comparative exploratory analysis. J Sex Med. 2020;17(2):289-299.

[39] Li R, Li B, Kreher DA, et al. Association between dysmenorrhea and chronic pain: a systematic review and meta-analysis of populationbased studies. Am J Obstet Gynecol. 2020. doi:10.1016/j.ajog.2020.03. 002 .

[40] Reis FM, Santulli P, Marcellin L, et al. Superficial peritoneal endometriosis: Clinical characteristics of 203 confirmed cases and 1292 endometriosis-free controls. Reprod Sci. 2020;27(1):309-315.

[41] Gracia CR, Sammel MD, Freeman EW, et al. Predictors of decreased libido in women during the late reproductive years. Menopause. 2004;11(2):144-150.

[42] Fuldeore MJ, Soliman AM. Prevalence and symptomatic burden of diagnosed endometriosis in the United States: National Estimates from a Cross-Sectional Survey of 59,411 Women. Gynecol Obstet Invest. 2017;82(5):453-461.

[43] Singh S, Soliman AM, Rahal Y, et al. Prevalence, symptomatic burden, and diagnosis of endometriosis in Canada: cross-sectional survey of 30000 women. J Obstet Gynaecol Can. 2020;42(7):829-838.

[44] Mabrouk M, Raimondo D, Parisotto M, et al. Pelvic floor dysfunction at transperineal ultrasound and voiding alteration in women with posterior deep endometriosis. Int Urogynecol J. 2019;30(9): $1527-1532$

[45] Mabrouk M, Del Forno S, Spezzano A, et al. Painful love: Superficial dyspareunia and three dimensional transperineal ultrasound evaluation of pelvic floor muscle in women with endometriosis. J Sex Marital Ther. 2020;46(2):187-196. 
[46] Burri A, Hilpert P, Williams F. Pain catastrophizing, fear of pain, and depression and their association with female sexual pain. J Sex Med. 2020;17(2):279-288.

[47] Neijenhuijs KI, Hooghiemstra N, Holtmaat $\mathrm{K}$, et al. The Female Sexual Function Index (FSFI) - a systematic review of measurement properties. J Sex Med. 2019;16(5):640-660.
[48] Meston CM, Freihart BK, Handy AB, et al. Scoring and Interpretation of the FSFI: what can be learned from 20 years of use? J Sex Med. 2020;17(1):17-25.

[49] Zarbo C, Brugnera A, Compare A, et al. Negative metacognitive beliefs predict sexual distress over and above pain in women with endometriosis. Arch Womens Ment Health. 2019;22(5):575-582. 